\title{
Feasibility Study of Quanzhou Maritime Silk Road Incense Culture Tourism Development
}

\author{
Cai-Zhen Hong \\ College of Applied Science and Technology, Quanzhou Normal University, Fujian, China \\ E-mail: hongcaizhen2@126.com
}

\begin{abstract}
Chinese incense culture has a long history, and is known with tea culture and flower culture as the three major cultural phenomena. Development of Quanzhou Maritime Silk Road incense culture tourism is to adjust tourism industrial structure, develop cultural creative tourism and promote Maritime Silk Road culture. It is feasible due to the exquisite life demand of of the people, historical background of Quanzhou Maritime Silk Road and the spice trade, and Chinese incense capital -- Yongchun Pushi incense technology. The integration of Quanzhou Maritime Silk Road incense culture and six elements of tourism industry can broaden the tourism industry chain, and promote the transformation and upgrading of tourism industry.
\end{abstract}

Keywords-Maritime Silk Road; Incense Cultural Tourism; Feasibility

\section{THE ORIGIN OF CHINESE INCENSE CULTURE}

The incense culture began in the ancient, germinated in the pre Qin period, started in the Qin and Han Dynasties, grew in Six Dynasties, completed in the Sui and Tang Dynasties, flourished in Song Dynasty, and wide spread in the Ming and Qing Dynasties. [1] Incense culture of Han nationality in China is a series of goods, technology, methods and habits, system and concept that gradually formed to reflect the Han nationality spirit and tradition by various spices production, processing, and use during the long course of history. Incense culture, tea culture, and flower culture is known as the three major cultural phenomena in China.

The history of burning incense by Chinese ancestors can be traced back to the late Neolithic age, about 6000 years ago. The reasons of burning incense by ancestors were to offer sacrifices to heaven, for mosquito repellent and exorcise of evil spirits. [2] Early ceremonial incense is mainly burning firewood and offerings (wine and grain offerings, etc.), such as Oracle bone inscription records of the Shang Dynasty "hand holding the burning wood" offering. Incense for life use also has a long history, living supplies Tao Xunlu emerged as early as 4000 to 5000 years ago. In the pre Qin period, the use of perfume bag, vanilla had been popular. At the time of the Warring States sophisticated smoked furnace Boshan furnace had been produced; in the Emperor Wudi of Han Dynasty period (about $120 \mathrm{BC}$ ), incense and incense burner had been popular in the north and south parts among the nobilities; in the early Eastern Han Dynasty, spice medicine was abundant, and was regarded as enjoyment of life, a method of removing dirty health; in the Wei and Jin Dynasties incense had been used by the literati; in the Northern Song Dynasty "fragrance is among all lanes". Rich category of aromatic plants were used for incense, expelling worm, medical and health and many other fields, and were used by smoked burn, wear, smoke bath, and beverage service etc.. Incense culture had become popular at that time. [3]

Incense use by the Ming Dynasty palace and folk was prevalent, not only related with the continuation of traditional culture, but also with Zheng He's seven voyages to the western seas. The trips strengthened relationships between China and many countries and regions in Asia and Africa, also introduced a large number of spcies and incense making skills from Somalia, Kenya, Indonesia and other contries. The incoming spices were maily pepper, sandalwood, etc. [4] In the book "Dream of Red Mansions" incense use was a microcosm of the life of Qing Dynasty nobles, the incense makeup, aromatherapy, incense accessories, incense ceremony, and incense industry is worth exploration. "Dream of Red Mansions" has rich description of the incense, the names of people and places have a fragrant aroma, such as Xiangling, Tan Yun, Sheyue, Heng Wu School, Daoxiang village, Hanxiangge, and Nuanxiangwu. Most main characters were related to incense. [5]

In The Qing Dynasty, Yunnan, Tibet, Sichuan, Shandong, Jiangsu, Zhejiang, Guangdong, Hunan and other places had temporary incense market, especially the West Lake in Hangzhou. West Lake incense market started from February fifteen to May fifth of lunar calendar, which was a busy time of the year. People gathered in the temples around the West Lake in Hangzhou for worship. Incense culture can be fully reflected by all the incense. The types of incense included sandalwood and joss stick, and daily trading volume was hundreds of pounds for sandalwood and around thousands for joss stick. A small amount of incense was burnt and the remaining was given to the monks. Monks also took this opportunity to sale the temple beads and other special items. Incense market of the West Lake shows the social life of the people of South of the Yangtze River in Qing Dynasty by the duration of the market, pilgrims source, praying, market and other aspects. [6]

In modern times, Chinese nation ill fated, incense cultural development had also been greatly depressed, and was limited in the altars and temples. Today a lot of people think incense is a religious culture and feudal superstition. It is exciting that through the 20th century the Chinese people gradually appreciate Chinese traditional incense culture. 


\section{II.FEASIBILITY STUDY OF QUANZHOU MARITIME SILK ROAD INCENSE CULTURAL TOURISM DEVELOPMENT}

\section{A. Background: Chinese Exquisite Leisure Life Demand}

Chinese incense culture is profound. From incense history, before the Han Dynasty incense was mainly Tangmu and etiquette incense; in Han, Wei and Six Dynasties Boshan type incense was popular; in Sui and Tang Dynasties, with the integration of Eastern and Western civilization, there was various usage of incense; during the Song and Yuan Dynasties, incense, tea, flower and pictures were four elegant things for upper class life; in the Ming Dynasty, incense, science, and Buddhism became a lesson to learn; in the Qing Dynasty prosperity, incense got into daily life of people, and a set of three pieces: furnace, bottles and boxes, became typical room layout. With the recession later and the invasion of the western culture, incense gradually no longer became noble and literati's leisure life. [7]

Natural flavor was used in the ancient incense, and now the chemical flavor has become the main raw material for incense. Many chemical processing technology and flavor spices is not healthy. But with the improvement of people's material and spiritual life level, more and more people love incense, understand incense, taste incense, and are committed to inheriting and developing the traditional culture of incense. In the fast pace of modern life, incense can eliminate all worries, purify mind and body. Therefore, the development of Quanzhou incense cultural tourism, meets the current needs of people on the exquisite leisure life.

\section{B. Historical Basis: the Maritime Silk Road and the Spice Trade of Quanzhou}

China has plenty of natural spice plant resources from the south to the north, but mainly concentrated in the south of Yangtze River area. The production is the largest in Guangxi, Guizhou, Hainan, Yunnan, Hunan, Guangdong, Fujian, Sichuan, and Hubei. According to incomplete statistics, at present the world has more than 3000 plants containing essential oil, but in the international market number of natural spices is only about 500 or so, and 100 to 200 industrial production and commercialization (nearly 60 families of plant). There are 400 species belonging to 62 families of plants in China, and about 120 kinds of natural spices are being produced. [8]

But in the pre Qin period, the earth climate was warm and cool, which was not suitable for the growth of plant spices, border and overseas spice medicine (incense, sandalwood, frankincense) had not yet been imported from the mainland, spice medicine is mainly local vanilla incense (mainly herbaceous), such as orchid, irises, Ai, pepper, cinnamon, etc.. The vanilla uses were very rich at that time. It had been recorded by Classic books such as "the Book of Songs", "Shangshu", "Book of Rites", "Rites of Zhou", "Zuo Zhuan", etc.. [2] During the territory expansion of the Qin and Han Dynasties, "Land Silk Road" and "Maritime Silk Road" opened, a number of spices were introduced to China from South China, South Asia and Europe. Incense, sandalwood etc. had been popular among the nobilities in the Han Dynasty. The prevalence of Buddhism and Taoism in the Han Dynasty promoted the development of incense culture. [9] The rapid development of the incense culture in Han Dynasty also had a great relationship with Emperor Wudi, who loved incense incredibly, which greatly boosted the incense market.

Before the Sui and Tang Dynasties, most of the best spices were from the offerings of other countries, and is a luxury in upper class, and is not popular in the middle and low classes. After the Tang Dynasty, the situation was completely different. A large number of spices were transported along the Silk Road across the Asian hinterland from the western regions to China. After the An-Shi rebellion north land Silk Road was blocked, south maritime Silk Road began to flourish with ship building and navigation technology improvement. A lot of spices entered the north from Guangdong, Guangxi, and Fujian.

Maritime technology in Song Dynasty was highly developed, the south "Maritime Silk Road" was more prosperous than the Tang Dynasty. Chinese exported goods were mainly gold, silver, copper, silk, porcelain, and imported goods were spice medicine, bead jade, ivory, and rhinoceros horn. [10] According to research, the import of the Song Dynasty spices amounted to tens of thousands of pounds per year, accounting for $1 / 4$ of the imported goods. [2] Incense, borneol, aloes and various spices from South Asia and Europe across the seas arrived in Guangzhou, Quanzhou and other southeast coastal ports, and then transported to the mainland. At the same time, the fragrance of musk from China was shipped to South Asia and Europe. The Shibo department in Quanzhou was the management of import and export trade agency in Song Dynasty. The spice trade tax was the country's main financial income. In the Song Dynasty, the government even monopolized the spice trade, and did not allow trade by people without permission. [9]

Huang Chunyan summarized in Table 1 the imported goods in Song Dynasty:

TABLE I. IMPORT COMMODITIES IN THE SONG DYNASTY

\begin{tabular}{|c|c|}
\hline Type & Name \\
\hline Treasures & $\begin{array}{c}\text { gold and silver, ivory, rhinoceros horn, } \\
\text { hawksbill, pearl, coral, etc. }\end{array}$ \\
\hline Spices & $\begin{array}{c}\text { incense, sandalwood, Benedict oak, } \\
\text { benzoin, musk wood, etc. }\end{array}$ \\
\hline medicine & pepper, ginseng, musk, etc. \\
\hline Normal goods & $\begin{array}{c}\text { silk cloth, some daily necessities cloth, } \\
\text { silk, pine board, folding fan, etc. }\end{array}$ \\
\hline Military supplies & Japanese knife, iron, sulfur, knife, furs, \\
etc.
\end{tabular}

Source: Huang Chunyan. Song Dynasty Overseas Trade, Beijing: Social Science Literature Press, 2003.

Since the sea opening in Western Han Dynasty, Southeast China had more than ten ports related to Maritime Silk Road. Until the Song and Yuan Dynasties, Guangzhou, Mingzhou (Ningbo), Quanzhou were the three largest trading ports.Song Taizu KaiBao 4th year (971 AC), the court first established the first Shibosi department in 
Guangzhou.During the Northern Song Dynasty, Guangzhou's foreign trade volume had been an absolute advantage among the three largest trading ports. In the Song Dynasty, spice medicine, for example, Shenzong Xining 10th year (1077 AC), Guangzhou, Hangzhou, and Mingzhou Port imported a total of 354,449 pounds, in which the Guangzhou port had 348,673 pounds; about $98.3 \%$ of the national total, Mingzhou had 4,739 pounds, 2nd largest among the three major ports.

In the 2nd year of Songzhezong (1087 AC), the Shibosi department was set up in Quanzhou, the official opening of Quanzhou port. In the middle of Southern Song Dynasty, overseas trade in Quanzhou developed rapidly, and the income almost catched up with the Guangzhou. Gandao 3rd year (1167 AC) Song Xiaozong gave 250,000 to Quanzhou Shibosi department to expand the scale of its overseas trade. At the end of the Southern Song Dynasty, Quanzhou's foreign trade exceeded Guangzhou. [11]

Yuan Dynasty was the most prosperous period of the development of overseas trade in Quanzhou. According to "The History of Yuan Dynasty, Volume 11," in addition to the import and export tax, only business tax was needed in Quanzhou when exporting goods to other places. At this time Quanzhou is the China's main customs, and overseas trade entered its peak time. The spice trade of Quanzhou in the Yuan Dynasty played an important role.

The Ming Dynasty was the second after the Song Dynasty that had its peak of tributary foreign flavor. Zheng He's expeditions played an important role in the spices trade. Zheng $\mathrm{He}$ expedition was because of the strong spice demand of the palace and folk, government's "universal submission" political purpose and looking for overseas spice. Ma Huan followed the Zheng He expeditions and in his books recorded that Zheng He's fleet arrived in Southeast Asia, Indian Ocean and East African countries, where spice habitated in history, such as Indonesia's Maluku islands (known as spice Islands), Somalia, West Asia, the Red Sea and the Persian Gulf area, that was famous in the ancient in the world for it rich spice. There was certain special spice in some of these countries.

\section{Current Heritage: the Technology of Yongchun Pu's Incense Production}

\section{1) Pu Shougeng and Spice Trade}

Quanzhou port started in the Tang Dynasty, prosperpous in the Song Dynasty, and reached its peak in late Song and early Yuan Dynasty. It was then recognized as the "Oriental first port", on a par with the port of Alexandria, Egypt. According to the historical records, in the 10th Century Quanzhou and Persia trade was frequent, and Islam was introduced into Quanzhou. Quanzhou is called "Citong" which is Arabic for "Zaitun". During the 100 years from the mid 13th century to the 14th century, a large number of Arabian and Persian Muslim businessmen flocked to Quanzhou, built Qingjing temple and Fan Fang. According to the estimate in the Song and Yuan Dynasties, foreigners accounted for half of the total population of Quanzhou. So far, there are more than 100,000 Arabian descendants in Quanzhou.
The development of Quanzhou Maritime Silk Road and spice trade benefited from the Arab traders, especially from an Arab descent, $\mathrm{Pu}$ Shougeng at the end of Song and beginning of Yuan Dynasty. Pu Shougeng (1245 -1284), was also named Hai Yun. He inherited his father, mainly engaged in overseas trade of bulk spices. "The History of the Song Dynasty, the Ying Chronicles" states: "Pu Shougeng, the head of Quanzhou Boshi, engaged in sea trade for 30 years". Pu Shougeng had a large number of sea ships. In 1973, a ship with capacity of 200 tons in the Southern Song Dynasty was unearthed; the ship was rich in spices relics. Some scholars believe that the ship may be spice ship of Pu's family, which is closely related to Pu's industry.

Quanzhou suffered no damage by the war in the late Song and early Yuan Dynasty thanks to Pu Shougeng. "The History of Yuan - Volume 94 "recorded, in the same year (1277 AC) of Pu Shougeng surrender, Yuan Shizu ordered to set up Quanzhou Shibosi department. Quanzhou overseas trade entered its golden period. Quanzhou had maritime trade with Japan in the east, and Southeast Asia, Persia, Arabia, and Africa in the West. Citong was one of the largest ports in the world, exporting ceramics, silk, tea, and iron, and importing spices, pepper, herbs, pearls etc.

$\mathrm{Pu}$ Shougeng had a great contribution to the development of Quanzhou port, as evidenced by the names related to Po Shougeng in Quanzhou.

2) Pu system Incense Heritage and Yongchun, China's Incense Capital

In Hui nationality with Surname Pu in Yongchun County, Quanzhou, a lot of people still follow the ancestral incense industry. Yongchun incense production process originated from $\mathrm{Pu} ; \mathrm{Pu}$ incense production industry, was originated from the Maritime Silk Road, a prosperous spice route according to the Arabians. Pu Lianggong, descendant of $\mathrm{Pu}$ Shougeng, still has the old trademark seal in Yongchun Wuli Street "Pu orchid room". He is well aware of the incense, sandalwood, herb orchid scent and a variety of spices. His son $\mathrm{Pu}$ Haixing thinks their family tradition is the fusion of the China incense culture and Arab descent incense production technology for a thousand years. He has opened a spice shop in Taobao called "Yun Lutang", and also trains his daughter knowledge of incense.

In May, 2014, China Light Industry Federation and the China daily goods industry officially awarded Yongchun Dapu town "Chinese incense capital - Yongchun Dapu" title, which is the only national incense base title in China. Dapu town has a history of more than 300 years of incense, 296 incense companies, with a staff of nearly 30 thousand people. More than a dozen of incense enterprises have annual revenue above 20 million Yuan, including Binda, Xinglong, Jinfeng, Lianfa, etc., and more than 1100 kinds of products. In 2013 the incense industry has produced a total 2.7 billion Yuan in revenue, and sales network all over the country. They were also exported to Europe, Southeast Asia and other regions. Dapu town, ancient city of Hebei, Qingyuan, Guangdong, and Xiamen Xiang'an are named "China's four biggest incense bases".

Yongchun incense enterprises are based on Maritime 
Silk Road culture, traditional Chinese medicine pharmacology, in the direction of culture return, and incense industry has gone beyond the traditional concept of worship activities, to home, health, cultural appreciation and higher level.They produced the linear incense and car incense device, a new type of incense products. The construction of incense industrial park is a key project of Fujian Province. The Dapu Binda incense factory has opened the Binda Incense Culture Industrial Park. In the simple and elegant incense Museum, you can experience the fun of "does it yourself" (DIY). Incense culture tourism industry will be an important Yongchun incense enterprises marketing, which has attracted many tourists from Shishi, Jinjiang, etc.. Traditional incense making process includes ten steps. In the outdoor, there will be a master to guide visitors to understand and experience the traditional process of incense. Indoor part of the layout is simple and elegant, incense culture related substance and lyre playing, and chess, calligraphy and painting are nicely integrated. Yongchun first incense workshop of Jiashunmei also transformed an imitation of Ming and Qing Gudacuo will be built, traditional incense making process will be open to visitors.

\section{CONCLUSIONS}

Maritime Silk Road incense culture can integrate with six elements of tourism. As mentioned above, the entrance ticket is the main expense of Quanzhou domestic and foreign tourists. Among the six elements, traveling, sightseeing, lodging, eating, accounted a larger proportion, shopping and entertaining accounted for a smaller proportion. Tourism industry chain is not perfect; tourism income structure is unreasonable.The development of cultural creative tourism, Maritime Silk Road cultural creative tourism can be used as a good example. The integration of the six elements of tourism and the incense culture can broaden the tourism industry chain, and extend the staying time of tourists in Quanzhou.

\section{ACKNOWLEDGEMENT}

This paper is funded by Quanzhou Normal University of the third batch of academic leaders training project, cultural research center of Chinese Academy of Social Sciences Southern Fujian culture research base (Quanzhou Normal University) project.

\section{REFERENCE}

[1] Fu Jingliang, China Incense Culture, Ji'nan: Qilu press, 2008, preface, p.3.

[2] Xiao Jun, "The Origin of Chinese Incense Culture", Journal of Yangtze University (SOCIAL SCIENCE EDITION), vol.9, pp.168-169, 2011.

[3] Fu Jingliang, China Incense Culture, Ji'nan: Qilu press, 2008, preface, pp. 3-5.

[4] Yan Xiao Qing. Zheng He, "Ming Dynasty and the Western Regions Tributary Trade with China", Research on Chinese Economic History, vol.2, 2012, pp. 180-185.

[5] Yan Xiaoqing, Zhang Tao, "Incense Story of 'Dream of Red Mansions', Study on the Ming and Qing Novels”, vol.3, 2008, pp. 139-149.

[6] Cai Yulong, "A brief discussion on the incense market in the southern cities in the Qing Dynasty based on the West Lake of Hangzhou, China" Histroy Curriculum,vol.20, pp. 24-29, 2010.

[7] China incense culture is broad and profound [EB/OL] http://chinakodo.com/post/189.html

[8] China Flavors \& Fragrances cosmetics industry association. History of Chinese flavor and Fragrance Development, Beijing: China Standard Press, 2001, pp.50-52.

[9] Three little knife, "Chinese Incense Culture evolution process", Tea Expo, vol.7, 2012, pp. 39-42.

[10] [Japanese] Sangyuanzhicang, Chen Yujing. Shougeng, Pu, Beijing: Zhonghua Book Company, 2009, p.23.

[11] Li Jun, "Comparative study of Guangzhou, Mingzhou (Ningbo) and Quanzhou port development during the prosperous period of 'Maritime Silk Road' in the Song and Yuan Dynasties", Southern heritage, vol.1, pp. 76-82, 2005. 